\title{
Desempenho e Qualidade dos Ovos de Codornas de Quatro Grupos Genéticos ${ }^{1}$
}

\section{Cleusa Móri ${ }^{2}$, Edivaldo Antônio Garcia ${ }^{3}$, Ana Cláudia Pavan ${ }^{4}$, Adriana Piccinin ${ }^{5}$, Miriani Rosa Scherer6, Carla Cachoni Pizzolante ${ }^{7}$}

RESUMO - Avaliou-se o desempenho e a qualidade dos ovos de codornas de corte de quatro grupos genéticos, utilizando-se 288 aves com 42 dias de idade, em delineamento em blocos ao acaso com quatro tratamentos (grupos genéticos A, B, C e D) e seis repetições de 12 aves cada. A partir da primeira semana de alojamento, estabeleceu-se o programa de luz, iniciando-se com 14 horas diárias de fotoperíodo, com aumentos sucessivos de 30 minutos por semana até que atingisse 17 horas diárias de fotoperíodo. Semanalmente, os ovos e as sobras de ração de cada parcela foram pesados, para determinação do peso médio dos ovos e do consumo médio diário de ração. A cada 28 dias, foram coletados e analisados três ovos/parcela/dia por três dias consecutivos, para avaliação da qualidade externa e interna. Foram detectadas diferenças significativas entre os grupos genéticos para massa de ovos e peso médio dos ovos, de modo que o grupo genético $\mathrm{B}$ apresentou média superior à dos demais. Para gravidade específica e porcentagem de casca, foram observadas diferenças significativas entre os grupos genéticos, com médias superiores para o grupo genético D. Os grupos genéticos testados apresentaram boa produção e qualidade de ovos, comprovando que estas codornas de corte podem ser utilizadas como matrizes de pintainhos de corte.

Palavras-chave: codornas de corte, desempenho, grupo genético, produção de ovos, qualidade dos ovos

\section{Performance and Egg Quality of Four Quail Genetic Groups}

\begin{abstract}
The study aimed to evaluate the performance and egg quality of four genetic groups selected for meat production. Two hundred and eighty eight quails 42 days old were used. The experiment design was the completely randomized blocks with four treatments (genetic groups A, B, C and D) and six replicates of 12 birds each. In the first week, it was given 14 hours of light with increases of 30 minutes per week until it reached 17 hours of light. Egg and feed were weighed once a week to determine egg weigh and feed consumption. Eighteen eggs from each replicate were collected and analyzed each 28 days period during three consecutive days to evaluate quality. There were significant differences among the genetic groups for egg weight and egg mass, and the genetic group B showed the higher values. Significant differences concerning specific gravity and shell percentage were observed among genetic groups and D group showed higher means for these characteristics. The genetic groups evaluated presented good results for egg production and egg quality, showing that these birds could be utilized as quali breeds.
\end{abstract}

Key Words: egg quality, egg production, genetic group, meat quail, performance

\section{Introdução}

Nos últimos anos, a coturnicultura tem despertado grande interesse de produtores, empresas e pesquisadores, por exigir investimentos e mão-de-obra menores que outras culturas. A codorna doméstica (Coturnix japonica) apresenta ciclo reprodutivo curto, precocidade sexual, boa fertilidade e ótima taxa de postura.

Aliada às qualidades produtivas das codornas, notou-se, na última década, mudança nos hábitos alimentares da população que favoreceram o aumento do consumo de ovos de codornas, presentes em restaurantes e churrascarias. Nos supermercados, podem ser encontradas embalagens de $1 \mathrm{~kg}$ de ovos, descascados ou em conserva, a preços baixos e com segurança sanitária, o que agrada donas de casa, que podem preparar novos pratos com maior facilidade e confiança no produto adquirido. Por estas razões, nos anos de 1999 e 2000, houve aumento significativo no plantel de codornas de aproximadamente $17 \%$, com aumento de $27 \%$ na produção de ovos. Em 2001, o plantel de codornas foi estimado em seis milhões de aves, com produção de ovos de 93.334 milhões de dúzias (IBGE, 2003).

\footnotetext{
1 Projeto financiado pela FAPESP. Parte da Dissertação de Mestrado da primeira autora.

2 Aluna de Pós-Gradução em Zootecnia (Doutorado) da Faculdade de Medicina Veterinária e Zootecnia - UNESP - Botucatu. (cleusa_móri@fca.unesp.br).

3 Professor do Departamento de Produção e Exploração Animal da Faculdade de Medicina Veterinária e Zootecnia - UNESP - Botucatu. (egarcia@fca.unesp.br).

4 Zootecnista. Mestre em Produção e Nutrição Animal pela Faculdade de Medicina Veterinária e Zootecnia FMVZ/UNESP - Botucatu (ana.pavan@fca.unesp.br).

5 Aluna de Pós-Graduação em Genética (Doutorado) do Instituto de Biociências IBB-UNESP - Botucatu.

${ }^{6}$ Zootecnista.

${ }^{7}$ Pesquisadora da Agência Paulista de Tecnologia dos Agronegócios - UDP - Brotas.
} 
Atenta à demanda do mercado consumidor, a Perdigão $\AA$, empresa do setor avícola, introduziu no Brasil uma nova variedade de codornas para produção de carne, que, aos poucos, foi denominada pelos produtores de linhagem italiana. Neste contexto, pesquisadores estão buscando melhor conhecimento das linhagens disponíveis, a fim de se estabelecer índices zootécnicos, contribuindo para o pleno desenvolvimento da cultura. Almeida (2001), estudando o efeito da interação linhagem e nível protéico da ração para fêmeas de codornas de corte em crescimento, relata que fêmeas da linhagem japonesa iniciam sua postura antes das fêmeas da linhagem italiana, indicando maior precocidade da primeira linhagem. As fêmeas da linhagem italiana, no período de 42 a 49 dias, apresentam menor consumo de alimento que aquelas da linhagem japonesa, indicando melhor capacidade de aproveitamento do alimento.

Singh \& Panda (1987) utilizaram quatro linhagens de codornas (Coturnix coturnix japonica); EL (linhagem de postura), WEL (linhagem de postura de ovos de casca branca), ML (linhagem de corte) e CL (linhagem de corte controle) para avaliarem o efeito da linhagem e das estações do ano sobre a qualidade do ovo. Os autores observaram diferenças significativas de linhagens e de estação do ano sobre a qualidade da gema e do albúmen e maior espessura da casca. Ricklefs \& Marks (1983) avaliaram a qualidade dos ovos de quatro linhagens de codornas selecionadas para ganho de peso às quatro semanas de idade e obtiveram diferenças significativas para porcentagem de gema.

Akbar et al. (1983) investigaram os efeitos do grupo genético, da idade e da dieta sobre a composição dos ovos e encontraram diferenças significativas entre os grupos genéticos para porcentagem de gema e de albúmen e peso da casca dos ovos. Contudo, Altan et al. (1998) e Piccinin (2002) não encontraram diferenças para porcentagem de gema e albúmen entre os grupos genéticos de codornas japonesas.

Entretanto, são poucas as informações sobre o potencial produtivo da linhagem italiana sobre a linhagem japonesa, em relação ao consumo de ração, à conversão alimentar por dúzia e quilograma de ovos e à qualidade dos ovos, desconhecendo-se, talvez, sua dupla aptidão.

Objetivou-se, com este estudo, avaliar o potencial de produção e a qualidade dos ovos de quatro grupos genéticos de codornas, disponibilizando informações adequadas, de modo a estabelecer seus índices zootécnicos e sua habilidade como matrizes para produção de codornas de corte.

\section{Material e Métodos}

Foram utilizadas 288 aves oriundas das granjas Coração de Leão (grupo genético C), localizada em Brasília/DF, Molino Blanco (grupo genético D), localizada no município de São Lourenço da Serra/SP e Suzuki (grupos genéticos A e B), localizada também em São Paulo. As aves foram adquiridas com um dia de idade e foram criadas em condições idênticas de manejo e alimentação até os 42 dias de idade, quando se iniciou o período experimental, que teve duração de 168 dias, correspondendo a seis ciclos de 28 dias. Aos 42 dias, as fêmeas foram alojadas em galpão de $15 \mathrm{~m}$ de comprimento e $7 \mathrm{~m}$ de largura, contendo 144 gaiolas metálicas, específicas para produção de ovos, das quais foram utilizadas 24 gaiola com $96 \mathrm{~cm}$ de comprimento, $33 \mathrm{~cm}$ de largura e $16 \mathrm{~cm}$ de altura, com três compartimentos cada uma e capacidade de 12 aves por gaiola. Cada compartimento foi equipado com um bebedouro tipo nipple e comedouro tipo calha, localizado frontalmente à gaiola. Para melhor conforto térmico das aves, as laterais do galpão foram equipadas com cortinas. A partir da primeira semana de alojamento, foi iniciado o programa de luz, com 14 horas diárias de fotoperíodo e aumentos sucessivos de 30 minutos por semana até atingir 17 horas diárias. As aves receberam ração e água à vontade durante todo período experimental. A ração foi fornecida duas vezes ao dia. Semanalmente, as eventuais sobras de ração foram pesadas em balança eletrônica para análise do consumo e da conversão alimentar. Diariamente, os ovos de cada parcela foram contados e os registros anotados em formulário próprio. Foram avaliadas a produção de ovos, a massa de ovos, a conversão alimentar por quilograma e por dúzia de ovos, a porcentagem de ovos quebrados e a mortalidade. Uma vez por semana, os ovos de cada parcela foram pesados e, a cada 28 dias, por três dias consecutivos, foi recolhida ao acaso uma amostra de três ovos de cada parcela, para avaliação do peso, da gravidade específica, das porcentagens de gema, albúmen e casca. Os animais foram alimentados, durante todo período experimental, com ração única, à base de milho e farelo de soja, com $20 \%$ de proteína bruta e $2.900 \mathrm{kcal}$ de energia metabolizável, conforme recomendações do NRC (1994) para codornas em postura. A composição percentual e calculada da ração encontra-se na Tabela 1 . 
Tabela 1 - Composição porcentual da ração experimental Table 1 - Percentual composition of the experimental ration

\begin{tabular}{lc}
\hline $\begin{array}{l}\text { Ingrediente } \\
\text { Ingredient }\end{array}$ & $\begin{array}{c}\text { Quantidade } \\
\text { Quantity }\end{array}$ \\
\hline Milho (Corn) & 56,33 \\
Farelo de soja (Soybean meal) & 33,32 \\
Óleo de soja (Soybean oil) & 2,860 \\
Sal (Salt) & 0,350 \\
Calcário (Limestone) & 5,350 \\
Fosfato bicálcico (Dicalcium phosphate) & 1,310 \\
Suplemento vitamínico e mineral & 0,300 \\
Vitamin and mineral supplement & \\
DL - Metionina (DL - Methionine) & 0,139 \\
Colina (Choline) & 0,048 \\
\hline Total (Total) & 100,00 \\
\hline Nutriente ${ }^{2}$ (Nutrient) & \\
Proteína bruta (\%) (Crude protein,\%) & 20,00 \\
Energia metabolizável (kcal/kg) & 2900 \\
Metabolizable energy (kcal/kg) & \\
Cálcio (\%) (Calcium, \%) & 2,500 \\
Fósforo disponível (\%) & 0,350 \\
Available phosphorus (\%) & \\
Metionina (\%) (Methionine, \%) & 0,450 \\
Metionina + Cistina (Methionine + Cystine) & 0,760 \\
Lisina (\%) (Lysine, \%) & 1,070 \\
\hline
\end{tabular}

* Composição por kg do suplemento vitamínico e mineral (Composition for $\mathrm{kg}$ of vitamin and mineral supplement): $\mathrm{Cu}: 8.000 \mathrm{mg}$; Fe: $50.000 \mathrm{mg}$; Mn: $70.000 \mathrm{mg}$; Zn: $50.000 \mathrm{mg}$; I: $1.200 \mathrm{mg}$; Se: $200 \mathrm{mg}$; Veículo QSP: 1.000 g; Vit. A: 7.000 .000 UI; vit. D3: 2.000 .000 UI; vit. E: $5.000 \mathrm{mg}$; vit. K3: $1.600 \mathrm{mg}$; vit. B2: $3.000 \mathrm{mg}$; vit. B12: 8.000 mcg; Niacina: (Niacin) 20.000 mg; Ácido pantotênico (Panthotenic acid): $5.000 \mathrm{mg}$; Antioxidante (Antioxidant): $15.000 \mathrm{mg}$; Veículo QSP: $1.000 \mathrm{~g}$

O delineamento experimental adotado foi o de blocos ao acaso com quatro tratamentos (quatro grupos genéticos A, B, C e D) e seis repetições de 12 aves cada. A análise dos resultados foi realizada segundo os procedimentos estabelecidos no General Linear Model do SAS® (SAS Institute, 1989). Para comparação entre médias, foi realizado o teste Tukey, utilizando-secomo nível de rejeição alfa igual a 0,05.

\section{Resultados e Discussão}

No decorrer do período experimental, a temperatura média registrada no interior do galpão foi de $21,3^{\circ} \mathrm{C}$ e a umidade relativa média do ar foi de $76,4 \%$, que sugerem que as aves não sofreram estresse térmico durante o período experimental e, portanto, seu desempenho não foi afetado por esse fator.

As características de desempenho e mortalidade estão apresentadas na Tabela 2.
Para produção de ovos, não foram detectadas diferenças estatísticas ( $p>0,05)$ entre os grupos genéticos, embora os grupos genéticos A e B tenham apresentado discreta tendência de superioridade na porcentagem média de produção em relação aos demais grupos. Esse resultado é similar ao relatado por Altan et al. (1998), que não encontraram diferenças significativas para produção de ovos de linhagens selecionadas para alto ganho de peso. Outros autores reportaram resultados contrários aos deste estudo (Minvielle et al., 2002; Piccinin, 2002; Anthony et al., 1990; Marks, 1979), pois obtiveram diferenças significativas para produção de ovos entre linhagens. As diferenças entre estes resultados e os obtidos na literatura podem ser explicadas pela variabilidade genética entre as aves utilizadas nas diferentes investigações.

Para massa de ovos, foram observadas diferenças estatísticas $(p<0,05)$ entre os grupos genéticos, com maior média para o grupo B. Este resultado está de acordo com os descritos por Singh \& Panda (1987), em que a linhagem selecionada para produção de carne apresentou massa de ovos superior às linhagens selecionadas para produção de ovos. Entretanto, Piccinin (2002) não encontrou diferenças entre os grupos genéticos de codornas japonesas estudados.

O consumo médio de ração por ave/dia e a conversão alimentar por dúzia de ovos não foram influenciados pelos grupos genéticos $(p>0,05)$. Diferentes autores encontraram resultados divergentes (Piccinin, 2002; Garcia, 2001; Masukawa et al., 2001; Murakami, 1991), o que pode ser explicado pelos diferentes níveis nutricionais fornecidos às aves, pelas diferenças entre os grupos genéticos e pelas aptidões das aves, uma vez que os autores estudaram linhagens voltadas para produção de ovos, que consomem quantidade de ração menor que aquelas voltadas para produção de carne.

Para conversão alimentar por massa de ovos, não foram observadas quaisquer diferenças $(p>0,05)$ entre os grupos genéticos avaliados. Do mesmo modo, Piccinin (2002), trabalhando com diferentes grupos genéticos de codornas japonesas, não observou diferença para essa característica. Singh \& Narayan (2002), investigando vários cruzamentos de linhagens de codornas para produção de carne, registraram conversões alimentares piores que as observadas neste estudo, o que pode ser explicado pelas diferenças entre os grupos genéticos utilizados em cada ensaio. 
Tabela 2 - Desempenho de quatro grupos genéticos de codornas para produção de carne Table 2 - Performance of four genetics groups of meat quail

\begin{tabular}{|c|c|c|c|c|c|c|c|}
\hline $\begin{array}{l}\text { Grupo } \\
\text { genético } \\
\text { Genetic } \\
\text { group }\end{array}$ & $\begin{array}{c}\text { Produção } \\
\text { de ovos }(\%) \\
\text { Egg } \\
\text { production (\%) }\end{array}$ & $\begin{array}{c}\text { Massa } \\
\text { de ovos }(\mathrm{g}) \\
\text { Egg } \\
\text { mass }(g)\end{array}$ & $\begin{array}{c}\text { Consumo } \\
\text { de ração }(\mathrm{g}) \\
\text { Feed } \\
\text { intake }(g)\end{array}$ & $\begin{array}{c}\text { Conversão } \\
\text { alimentar/dúzia } \\
\text { Feed } \\
\text { conversion/dozen }\end{array}$ & $\begin{array}{c}\text { Conversão } \\
\text { alimentar } / \mathrm{kg} \\
\text { Feed } \\
\text { conversion } / \mathrm{kg} \\
\end{array}$ & $\begin{array}{c}\text { Ovos } \\
\text { quebrados (\%) } \\
\text { Broken eggs }(\%)\end{array}$ & $\begin{array}{r}\text { Mortalidade }(\%) \\
\text { Mortality }(\%)\end{array}$ \\
\hline$\overline{\mathrm{A}}$ & 84,35 & $11,10^{\mathrm{a} b}$ & 37,26 & 0,58 & 3,82 & 1,18 & 9,72 \\
\hline B & 84,49 & $11,32^{\mathrm{a}}$ & 37,99 & 0,59 & 3,77 & 0,70 & 13,89 \\
\hline $\mathrm{C}$ & 80,25 & $10,56^{\mathrm{ab}}$ & 38,11 & 0,59 & 3,87 & 1,12 & 9,72 \\
\hline D & 80,00 & $10,30^{b}$ & 37,82 & 0,60 & 3,98 & 1,22 & 12,50 \\
\hline Média & 82,27 & 10,82 & 37,80 & 0,59 & 3,86 & 1,06 & 11,46 \\
\hline $\begin{array}{l}\text { Mean } \\
\text { CV }(\%)^{1}\end{array}$ & 5,46 & 5,80 & 2,48 & 8,24 & 10,36 & 52,82 & 100,91 \\
\hline
\end{tabular}

1 Coeficiente de variação (Coefficient of variation).

$a, b$ Letras diferentes na mesma coluna indicam diferenças significativas $(p<0,05)$ entre os grupos genéticos.

$a, b$ Small letters in the same column indicate significant differences $(p<.05)$ among genetic group.

Não foram observadas diferenças significativas ( $p>0,05)$ entre os grupos genéticos para porcentagem de ovos quebrados. Nas condições em que este experimento foi realizado, a porcentagem de ovos quebrados foi uma variável de difícil interpretação, por apresentar alto coeficiente de variação, podendo indicar que o fator considerado nesse experimento (grupo genético) não foi o principal responsável pela incidência de ovos quebrados em codornas para produção de carne. Minvielle et al. (2000), estudando diferentes linhagens de codornas japonesas, observaram efeito de linhagem sobre a porcentagem de ovos quebrados.

Não foi constatado efeito significativo $(p>0,05)$ de grupo genético para mortalidade, que, na maioria das vezes, foi atribuída a causas desconhecidas. Entretanto, foram observados alguns casos de morte por prolapso do oviduto das aves. Minvielle et al. (2000) verificaram porcentagens superiores às deste estudo, porém, o período analisado por esses autores foi de 21 meses.

As características da qualidade dos ovos de codornas para produção de carne são apresentadas na Tabela 3.

Foi observada diferença significativa $(\mathrm{p}<0,05)$ entre os grupos genéticos para peso médio dos ovos, com maior média para o grupo genético $\mathrm{B}$, que não diferiu estatisticamente do grupo genético C. Esses resultados corroboram os relatados na literatura (Piccinin, 2002; Minville et al., 2000; Altan et al., 1998; Anthony et al., 1990; Singh \& Panda, 1987; Bacon et al., 1986; Ricklefs \& Marks, 1983), que afirmam haver diferença significativa entre diferentes grupos genéticos para essa característica, encontrando-se, no entanto, pesos médios dos ovos inferio- res (10,58 a 12,51) aos deste estudo. Segundo Marks (1991), as linhagens selecionadas para alto ganho de peso apresentam maior peso dos ovos que linhagens não selecionadas para essa característica, uma vez que o peso dos ovos apresenta alta correlação com peso corporal da ave.

Com relação à gravidade específica, observou-se diferença significativa $(\mathrm{p}<0,05)$ apenas entre os grupos genéticos A e D, de forma similar aos dados encontrados na literatura (Yannakopoulos \& TserveniGousi, 1986; Harms et al., 1983).

Para porcentagem de gema e albúmen não foram observadas diferenças $(p>0,05)$ entre os grupos genéticos, como nos trabalhos de Piccinin (2002), Altan et al. (1998), Anthony et al. (1990), Singh \& Panda (1987), que não verificaram diferenças significativas entre linhagens de codornas japonesas para essas características. Todavia, Minvielle et al. (2002), Nestor et al. (1996) e Ricklefs \& Marks (1983) encontraram diferenças significativas entre linhagens de codornas japonesas para porcentagem de gema e de albúmen, com valores de porcentagem de gema superiores aos do presente estudo (32,6 vs. 36,8\%).

Em relação à porcentagem de casca, foram encontradas diferenças significativas $(p<0,05)$ entre os grupos genéticos de codornas para produção de carne, com maior média para o grupo genético D. Constatou-se também que este grupo genético apresentou menor peso dos ovos. Esse resultado concorda com diversos autores (Minvielle et al., 2002; Piccinin, 2002; Anthony et al., 1990; Singh \& Panda, 1987), que registraram diferenças significativas entre porcentagens de casca de ovos de linhagens selecionadas para 
Tabela 3 - Qualidade dos ovos de quatro grupos genéticos de codornas de corte Table 3 - Egg quality of four genetic groups of meat quail

\begin{tabular}{|c|c|c|c|c|c|}
\hline $\begin{array}{l}\text { Grupo } \\
\text { genético } \\
\text { Genetic } \\
\text { group } \\
\end{array}$ & $\begin{array}{c}\text { Peso médio } \\
\text { dos ovos }(\mathrm{g}) \\
\text { Mean egg weight } \\
(\mathrm{g})\end{array}$ & $\begin{array}{l}\text { Gravidade } \\
\text { específica } \\
\text { Especific } \\
\text { gravity }\end{array}$ & $\begin{array}{l}\text { Porcentagem } \\
\text { de gema } \\
\text { Percentage } \\
\text { of yolk } \\
\end{array}$ & $\begin{array}{l}\text { Porcentagem } \\
\text { de albúmen } \\
\text { Percentage } \\
\text { of albumen } \\
\end{array}$ & $\begin{array}{c}\text { Porcentagem } \\
\text { de casca } \\
\text { Percentage } \\
\text { of shell } \\
\end{array}$ \\
\hline$\overline{\mathrm{A}}$ & $13,03^{b c}$ & $1,072^{\mathrm{b}}$ & 30,19 & 61,83 & $7,98^{\mathrm{b}}$ \\
\hline B & $13,45^{\mathrm{a}}$ & $1,073^{\mathrm{ab}}$ & 29,96 & 61,98 & $8,06^{\mathrm{b}}$ \\
\hline $\mathrm{C}$ & $13,18^{\mathrm{ab}}$ & $1,073^{\mathrm{ab}}$ & 29,97 & 61,97 & $8,06^{\mathrm{b}}$ \\
\hline $\mathrm{D}$ & $12,81^{\mathrm{c}}$ & $1,074^{\mathrm{a}}$ & 29,61 & 62,08 & $8,31^{\mathrm{a}}$ \\
\hline Média & 13,12 & 1,073 & 29,93 & 61,97 & 8,10 \\
\hline \multicolumn{6}{|l|}{ Mean } \\
\hline $\mathrm{CV}(\%)^{1}$ & 2,59 & 2,06 & 2,44 & 1,22 & 2,75 \\
\hline
\end{tabular}

produção de carne e ovos. Akbar et al. (1983) relataram que as linhagens atuais selecionadas para produção de ovos apresentam maior espessura de casca e maior resistência à quebra, em resposta à seleção para essas características.

\section{Conclusões}

As informações disponibilizadas neste estudo indicam que os grupos genéticos de codornas de corte apresentam capacidade de produção de ovos de qualidade, indicando que as fêmeas possuem habilidade como matrizes de pintainhos de corte de codornas.

\section{Literatura Citada}

ALMEIDA, M.I.M. Efeito de linhagem e de nível protéico sobre o desempenho e características de carcaça de codornas (Coturnix sp) criadas para corte. Botucatu: Universidade Estadual Paulista, 2001. 96p. Tese (Doutorado em Melhoramento Genético) - Universidade Estadual Paulista, 2001.

ALTAN, O.; OGUZ, I.; AKBAS, Y. Effects of selection for body weight and age of hen on egg characteristics in japanese quail (Coturnix coturnix japonica). Turkish Journal Veterinary Animal Sciences, v.22, n.6, p.467-473, 1998.

AKBAR, M.K.; GAVORA, J.S.; FRIARS, G.W. et al. Composition of eggs by commercial sizes categories: Effects of genetic group, age, and diet. Poultry Science, v.62, n.6, p.925-933, 1983.

ANTHONY, N.B.; EMMERSON, D.A.; NESTOR, K.E. et al. Divergent selection for body weight and yolk precursor in Coturnix coturnix japonica. 8. A summary of correlated responses. Poultry Science, v.69, n.10, p.1055-1063, 1990.

BACON, W.L.; NESTOR, K.E.; LONG, D.W. divergent selection for body weight and yolk precursor in Coturnix coturnix japonica. 6. Correlated response in plasma calcium and egg shell traits. Poultry Science, v.65, n.2, p.355-359, 1986.

GARCIA, E.A. Níveis nutricionais e métodos de muda forçada em codornas japonesas (Coturnix coturnix japonica).
Botucatu: Universidade Estadual Paulista, 2001. 111p. Tese (Livre Docência) - Universidade Estadual Paulista, 2001.

HARMS, R.H.; JUNQUEIRA, O.M.; WILSON, H.R. Specific gravity of turkey and Bobwhite quail eggs as influenced by time of oviposition. Poultry Science, v.62, n.7, p.13251326, 1983

INSTITUTO BRASILEIRO DE GEOGRAFIA ESTATÍSTICA- IBGE. Sistema IBGE de recuperação Automática. Disponível em: <http://www.ibge.br/sidra>Acesso em: 30 de agosto, 2003

MARKS, H.L. Changes in unselected traits accompanying longterm selection of four-week body weight in Japanese Quail. Poultry Science, v.58, n.2, p.269-274, 1979.

MARKS, H.L. Feed efficiency changes accompanying selection for body weight in chickens and quail. World's Poultry Science, v.47, p.197-212, 1991.

MASUKAWA, Y.; FERNANDES, E.B.; MORAES, V.M. et al. Níveis de cálcio da dieta sobre o desempenho e a qualidade da casca de ovos de codornas japonesas. ARS Veterinária, Jaboticabal, v.17, n.2, p.144-148, 2001.

MINVIELLE, F.; MILLS, A.D.; FAURE, J.M. et al. Fearfulness and performance related traits in selected lines of japanese quail (Coturnix japonica). Poultry Science, v.81, n.3, p.321326, 2002.

MINVIELLE, F.; MONVOISIN, J.L.; COSTA, J. et al. Longterm egg production and heterosis in quail lines after withinline or reciprocal recurrent selection for high early egg production. British Poultry Science, v.41, n.2, p.150-157, 2000.

MURAKAMI, A.E. Níveis de proteína e energia em dietas de codornas japonesas (Coturnix coturnix japonica) nas fases de crescimento e postura. Jaboticabal: Universidade Estadual Paulista, 1991. 92p. Tese (Doutorado em Zootecnia) - Universidade Estadual Paulista, 1991.

NESTOR, K.E.; BACON, W.L.; ANTHONY, N.B. et al. Divergent selection for body weight and yolk precursor in Coturnix coturnix japonica. 11. Correlated responses over thirty generations. Poultry Science, v.75, n.4, p.472-477, 1996.

NATIONAL RESEARCH COUNCIL - NRC. Nutrient requirements of poultry. Washington, D.C.: National Academy Press. 9.ed. 1994. 156p.

PICCININ, A. Efeito da interação genótipo-ambiente nas características dos ovos de codornas (Coturnix coturnix 
japonica) e sua curva de produção. Botucatu: Universidade Estadual Paulista, 2002. 53p. Dissertação (Mestrado em Ciências Biológicas) - Universidade Estadual Paulista, 2002.

RICKLEFS, R.E.; MARKS, H.L. Egg characteristics of lines japanese quail selected for four-week body mass. Poultry Science, v.62, n.6, p.1330-1332, 1983.

STATISTICAL ANALYSES SYSTEM - SAS. User's guide: statistics. Cary: 1989.

SINGH, R.V.; NARAYAN, R. Produção de codornas nos trópicos. In: SIMPÓSIO INTERNACIONAL DE COTURNICULTURA, 1., 2002, Lavras. Anais... Lavras, 2002. p.27.
SINGH, R.P.; PANDA, B. Effect of seasons on physical quality and component yields of egg from different lines of quail. Indian Journal of Animal Science, v.57, n.1, p.50-55, 1987.

YANNAKOUPOULOS, A.L.; TSERVENI-GOUSI, A.S. Quality characteristics of quail eggs. British Poultry Science, v.27, n.2, p.171-176, 1986.

Recebido em: 05/03/04

Aceito em: 06/04/05 